\title{
A dramaturgia do eu na vida de todos os dias: Vou a tua casa, Saudades do tempo em que se dizia texto e Actor
}

\author{
Mónica Guerreiro
}

Título: Vou a tua casa - lado a (primeira parte da trilogia Vou a tua casa). Dramaturgia, concepção, textos originais e interpretação: Rogério Nuno Costa. Fotografia e design: Luísa Casella. Local e datas de apresentação: casas dos espectadores, entre 15 de Agosto de 2003 e 18 de Março de 2004.

Título: Saudades do tempo em que se dizia texto. Dramaturgia, concepção e interpretação: Rogério Nuno Costa. Apoio cenográfico: F. Ribeiro. Figurino:Tânia Franco. Residência de movimento: Marina Nabais. Desenho de som: André Castro. Video: Sílvia Firmino. Fotografia e design: Luísa Casella. Local e data de estreia:Teatro Taborda, Lisboa, 28 de Novembro de 2003; reposição: Casa Municipal da Juventude do Laranjeiro, Janeiro de 2004.

Titulo: Actor. Dramaturgia, concepção, textos originais e interpretação: Rogério Nuno Costa. Espaço: F. Ribeiro. Figurino: Tânia Franco. Video: Rui Ribeiro. Luz: José Álvaro. Som: Carlos Morgado. Residência de movimento e assistência geral ao espectáculo: Marina Nabais. Colaboração artística: Miguel Pereira. Design gráfico: Ana Calhau. Fotografia: Luísa Casella. Produção: Centro Cultural de Belém. Local e data de estreia: Sala de Ensaio do Centro Cultural de Belém, BoxNova, Lisboa, 26 de Junho de 2004; reposição: Casa de Teatro de Sintra - Chão de Oliva, Julho de 2004.

Pode colocar-se o problema ao contrário do que tentou Goffman (que, num acesso de ladroagem bem humorada, quase-cito no meu intitulado): e se um estranho de repente Ihe entrasse pela casa adentro dizendo-se actor e propondo uma outra fórmula de experiência dramática - que observasse não apenas os preceitos curriculares mas, também, procurasse levar mais longe a percepção, por parte do agora feito espectador, da teatralidade latente nos objectos de que se rodeia? Invadir a intimidade e apoderar-se - ainda que por breves instantes - de parte da privacidade de um alguém que observa sabendo-se interpelado são, para Rogério Nuno Costa (n.1978, Braga), os alicerces do projecto Vou a tua casa, de que se cumpriu já a primeira de três versões (a segunda a decorrer em qualquer sítio da cidade à escolha do espectador e a terceira na casa do Rogério), um processo que deverá terminar em Agosto de 2005.

Ir a casa dos espectadores que o solicitassem, explica Rogério', não era verdadeiramente o mais importante: 0 espectro de possibilidades aberto pelos milhares de adereços de cena diferentes, e de hipóteses de inflexão dramatúrgica a cada esquina e divisão, ofereciam um desafio sempre renovado e que se apresentava, para o espectador, como uma

1 Em apresentação pública que finalizou a primeira fase do projecto, no Centro em Movimento, dia 19 de Março de 2004.

${ }^{2}$ Entre outros traços, estes distinguiram a sessão apresentada na casa em que habitava, a 23 de Agosto de 2003. aventura renovada. Porque, mais que servir teatro ao domicilio, tratava-se aqui de domiciliar uma teatralidade possivel, sorvida das próprias circunstâncias que o actor encontra e integra em tempo real - cita-se o título do livro de cabeceira, por exemplo, interpelando-se o espectador, e alguns seus traços característicos, como constituintes da trama dramática². Num revelador texto publicado na novel revista Artinsite, edição da Transforma A.C., Rogério elabora em redor do conceito da site-specific art, explicando a dada altura que a sedimentação, no corpo e na percepção do performer, dos elementos constituintes de um determinado topos precede qualquer hipótese de experiência profunda das potencialidades abertas por essa intervenção. Não obstante esta premissa, o facto é que a presença de um outro, espectador, transfigura a acção para a retirar já da fase de processo: enquanto explora o espaço em que entra pela primeira vez, Rogério-actor deixa atrás de si sinais do percurso do espectáculo em que já nos encontramos, marcações que, por um lado, evidenciam a teatralidade indisfarçável do exercício (não é por acaso que fala deste como o seu trabalho "mais teatral") e, por outro, alteram o figurino da habitação do espectador, cúmplice activo mas absolutamente desconhecedor do que se passará.

Este carácter de transformação efémera, inerente ao enunciado da performance, funciona como princípio de acção para Vou a tua casa: a saída do actor coincide com o apagamento de todas as marcas da sua presença, e com a mesma sensação de abandono presente em cada correr da cortina. Contudo, a reciprocidade da experiência assume aqui contornos talvez menos habituais: a imprevisibilidade está presente (ainda que em doses diferenciadas) para espectador e actor; a lógica espacio-temporal, se bem que sujeita à apropriação criativa por parte do autor/actor, é em primeira instância decisão do espectador, usufrutuário; a fragilidade relativa do papel do actor, longe da segurança do palco demarcado e preparado, potencialmente mais em posição de convidado (com o desconforto que esse papel implica) do que de condutor da acção.

Até que ponto consegue Rogério Nuno Costa, com esta criação ainda em evolução, encetar uma estratégia de subversão dos modelos convencionais de representação? Possivelmente, só o desenrolar do projecto o dirá com propriedade. Mas, para entrar na banalidade das definições - e sem que seja preciso abordar detalhes do conteúdo do espectáculo, o qual se alongava em formato de monólogo 


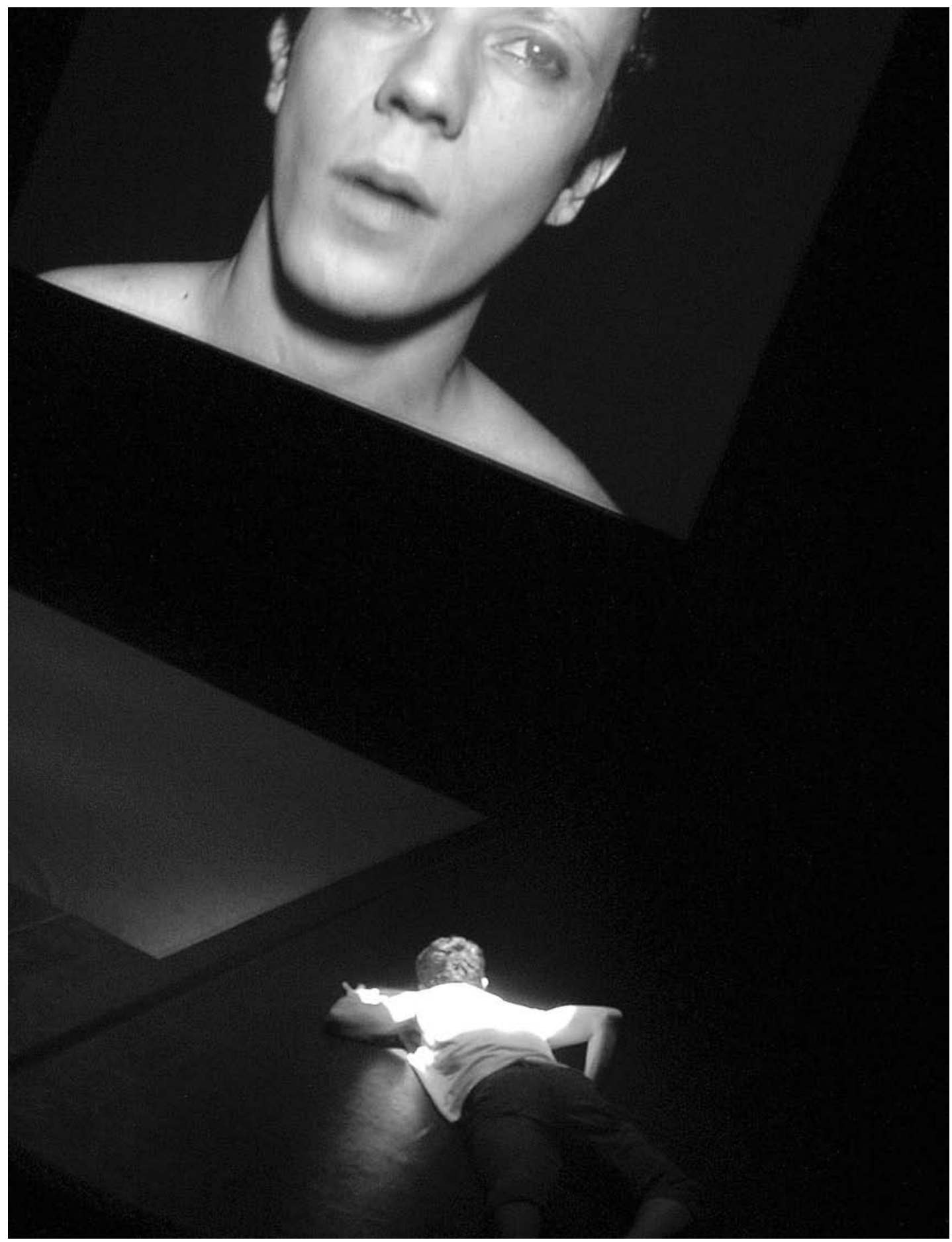

"acompanhado" acerca da vivência urbana contemporânea e de uma aventura romântica falhada, com contornos poéticos, banda sonora "de trazer por casa" e mensagens subliminares - diria por ora que a acepção de teatro como "acto da vontade" (Brook) é levada ao extremo por Rogério Nuno Costa como pretexto para a consagração do mínimo denominador comum: uma artificialidade construida e um espectador. Ou seja, um espaço comum, um querer ver e um querer ser visto.

lsto não é performance, é teatro

Aquilo que de mais estimulante, contudo, tem sido produzido por Rogério Nuno Costa (e, sem que me caiba avançar com justificações, também menos divulgado), inscreve um outro modus operandi e toda uma outra agenda de interesses.
Mas não seria rigorosa se dissesse que há uma alteração radical: a necessidade de estabelecer cada nova investida criativa como um resultado da anterior, pesando falhas e êxitos, cunha todo o trabalho autoral de RNC, e estabelece aquilo que, para mim, é uma característica fundamental no seu ainda curto percurso, que chamaria de inscrição do breviário quotidiano na construção dramática. Conquanto Vou a tua casa desenhasse um projecto intimista e construído para assim se apresentar, os seus mais recentes projectos - Saudades do tempo em que se dizia texto e Actor - encaminham-se para o que se poderia chamar de baliza oposta a esse: é o criador quem convida a entrar no espaço da sua privacidade, dos seus fantasmas, das suas paixões e medos, de uma forma arrojada e sem a protecção que uma 
Saudades do tempo em que se dizia texto, fot. Luisa Casella.

personagem dramática poderia oferecer à fragilidade que advém de tal exposição. 0 motivo central destes dois espectáculos pode resumir-se da forma simples e univoca que introduz qualquer trama biográfica: um dia na vida de Rogério Nuno Costa, incluindo viagem ao seu passado, sonhos e aspirações. A suposta "banalidade" da sua vida fornece mais material de exploração, e de inspiração, que o opus dramático que tem vindo a ser produzido ao longo dos séculos. São, pois, projectos de uma unicidade notável, onde uma dramaturgia fundada na experiência individual - sem a habitual transferência - constrói ficções que não o são exactamente, e que fabricam a cada momento, com uma inventividade quase pueril, essa estranheza e esse descentramento.

Em ambas as peças, os detalhes pessoais, que podemos supor subjectivos pela coincidência entre biografador e biografado, são permanentemente cruzados com informação factual sobre a sua formação profissional e sobre a sua admissão no meio artístico, como intérprete e como criador, além de outros dados pessoais ${ }^{3}$. 0 que há aqui de mais extraordinário, contudo, é o facto de estas peças esboçarem já não uma aproximação a um modelo e um registo próprios, mas uma maturação dessas reflexões, como se um processo de questionamento, tentativa e erro estivesse há muito por trás da sua feitura.

Saudades... é o típico espectáculo de despedida de carreira:

${ }^{3}$ Como o número de telefone, a morada, as preferências pessoais ou a canção que estava no top de airplay na semana em que nasceu. Rogério queria um espectáculo que fosse "a sua cara", ao mesmo tempo que desejava

"violentar-se" pela obrigação de se confrontar com textos, pelo que pediu a dez pessoas com quem

trabalhou que thos escolhessem, abordando-

os de formas pouco convencionais. elencam-se colaboradores e mestres, monta-se a feira das vaidades e serve-se um tour de force de 180 minutos, onde um actor sozinho em palco (que interpreta, dirige e opera também luzes e som) presta homenagem a si mesmo, num estilo auto-referencial e quase onanista. Extremamente ambicioso nos seus pressupostos, e mais ainda na concretização (porque o tema do espectáculo não é o teatro, nem a dramaturgia, nem um suposto "antigamente" da prática cénica clássica, mas sim o seu protagonista, Rogério Nuno Costa), Saudades... permitiu conhecer o programa que este jovem criador privilegia nas suas investigações: a construção de espectáculos-tese, para um intérprete, cuja identificação se confunde com a da personagem construida, a qual fala de si. Esta aparente confusão entre pessoa, persona e personagem tem proporcionado algumas acusações de narcisismo e megalomania, mas é impossivel não ler nesta vontade e neste esforço uma evidência: trata-se de um dos mais incomuns

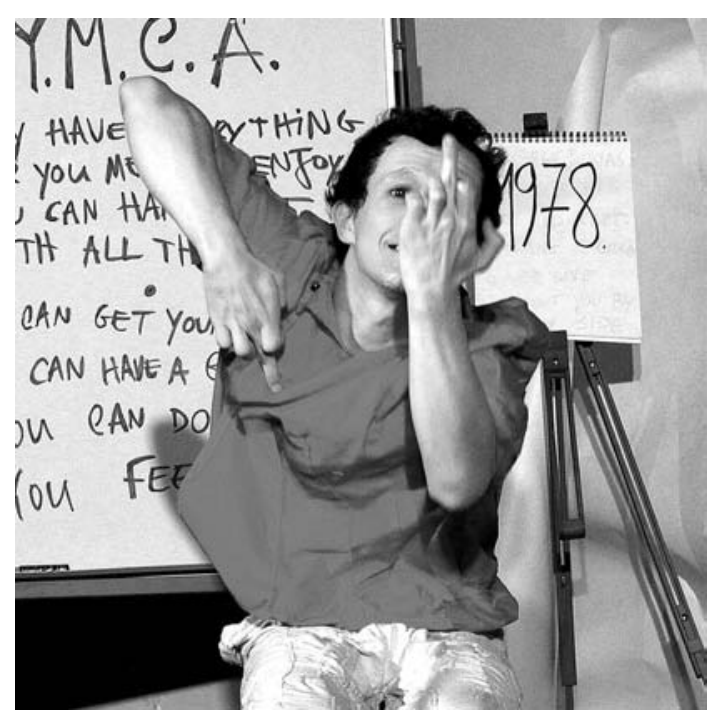

objectos nascidos da nova geração portuguesa de fazedores de teatro, pela constante interpelação das suas experiências pessoais e geracionais e pela sua inserção, a frio e quase sem intermediação, no espaço público de apresentação. Falamos de projectos de originalidade absoluta, em que muito pouco da linhagem tradicional resta para ser trabalhado, e em que o autor se anula por excesso de exposição, por descarnamento total daquilo que são "as vergonhas": a falta de preparação convencional para a actividade artística profissional, por exemplo.

E é esse o exercício primordial esboçado em Actor: a disponibilização do guião, logo ao início do espectáculo, e a assunção do papel do autor como apresentador e conteúdo do mesmo espectáculo, são as características que desde logo introduzem estranheza. A tese: a formação do actor; a formação do bailarino; como se define um espectáculo (teatro, dança, etc.). Enquanto isso, enquadram-se conceitos do academismo na prática efectiva para verificação da sua acuidade, discutemse os mecanismos da mentira na sugestão performativa e, já que estamos nisso, retoma-se o dogma da manipulação: até onde vai a representação?

A Rogério Nuno Costa podem apontar-se os defeitos da juventude, da investida talvez precipitada num filão de frutos maduros, mas que rapidamente se acabam: até porque os seus trabalhos ameaçam a espaços uma auto-explicação excessiva, uma inclinação para a demonstração da equação que talvez devesse ter ficado com uma incógnita por desvendar. Mas não se lhe pode exigir que modifique o seu objecto de estudo primordial: os espectáculos são interessantes porque se apresentam como problemas que se resolvem a si próprios, mas isso só é assim porque correspondem ao trabalho de Rogério Nuno Costa de se confrontar com os seus dilemas. Um actor que tivesse passado por uma instituição de ensino do seu oficio nunca teria os mesmos problemas de "certificação" ou de "identidade": é-se actor porque se trabalhou para isso, porque se nasceu assim, porque se estudou? E bailarino? Este criador e intérprete anunciou-se como uma alternativa, mesmo entre os seus pares, porque decidiu fazer de si mesmo, das suas vivências e ansiedades, um leitmotiv pessoal, ainda que partilhado por muitos na sua geração: questionar os formatos, os truques e as "bengalas" tradicionais dos nossos actos de representação. 